\title{
Burkholderia cepacia complex: clinical course in cystic fibrosis patients
}

\author{
Tania Wrobel Folescu ${ }^{1 *}$, Claudia Henrique da Costa ${ }^{2}$, Renata Wrobel Folescu Cohen ${ }^{1}$, \\ Orlando Carlos da Conceição Neto ${ }^{3}$, Rodolpho Mattos Albano ${ }^{4}$ and Elizabeth Andrade Marques ${ }^{5}$
}

\begin{abstract}
Background: Pulmonary deterioration after B.cepacia complex (BCC) colonization has a heterogeneous pattern. The aim was to investigate the clinical outcome of BCC colonization in CF patients chronically colonized with P. aeruginosa.
\end{abstract}

Methods: CF patients chronically colonized with P. aeruginosa were divided into three groups: intermittent (I), chronic (II) and no colonization (III) with BCC. Body mass index (BMI) percentile and spirometric parameters were analyzed at three different times in each group.

Results: Fifty-six patients chronically colonized with P. aeruginosa were included. Of these, 27 also had evidence of BCC colonization (13 intermittent and 14 chronic). BMI percentile was significantly lower among patients chronically colonized by both $P$. aeruginosa and BCC. Mean values of FEV $\mathrm{F}_{1}$ and FVC \% were also significantly lower in these patients, both at the time of chronic BCC colonization and 24 months forward.

Conclusions: Chronic BCC colonization is associated with significant loss of lung function. Lower BMI might be a risk factor for chronic BCC colonization, preceding these events.

Keywords: Cystic fibrosis, Burkholderia cepacia complex, Respiratory Function Tests, Body mass index

\section{Key messages}

- Chronic BCC colonization is associated with significant loss of lung function

- Lower BMI might be a risk factor for chronic BCC colonization

\section{Background}

Respiratory disease is the major cause of morbidity and mortality in cystic fibrosis (CF) patients. The majority of CF patients develop chronic infection by Pseudomonas aeruginosa, which is associated with impaired lung function and decreased survival in CF [1].

Burkholderia cepacia complex (BCC) is now recognized as a group of opportunistic pathogens in CF patients, usually associated with poor prognosis and patient-topatient transmissibility. The exact pathophysiology of BCC

\footnotetext{
* Correspondence: taniafolescu@hotmail.com

'Department of Pediatric Pulmonology, Instituto Fernandes Figueira (Fundação Oswaldo Cruz, Ministério da Saúde), Av. Rui Barbosa, 716, 2nd floor, Flamengo, Zip Code: 22250-020 Rio de Janeiro, RJ, Brazil Full list of author information is available at the end of the article
}

colonization/infection remains unclear, and pulmonary deterioration has a heterogeneous pattern, leading to a fulminant development in almost $30 \%$ of patients $[2,3]$.

Loss of lung function is still one of the main factor that contribute to mortality in CF [4]. Therefore, spirometric measurements - in particular, forced expiratory volume in $1 \mathrm{~s}\left(\mathrm{FEV}_{1}\right) \%$ predicted and forced vital capacity (FVC) \% predicted - are important surrogate measures of disease progression [4]. Nutritional status has a strong positive association with pulmonary function and survival in CF. Attainment of normal body mass index (BMI) is one of the major goals for CF treatment.

The aim of this study was to investigate the clinical outcome of BCC colonization in CF patients who were previously chronically colonized with $P$. aeruginosa.

\section{Methods}

This is a retrospective study performed in two CF centres in Rio de Janeiro, Brazil: Instituto Fernandes Figueira (Fundação Oswaldo Cruz, Ministério da Saúde), for children/adolescents, and Hospital Universitário 
Pedro Ernesto - HUPE (Universidade do Estado do Rio de Janeiro - UERJ), for adults. Approval was obtained from the ethics committee on both institutions.

In both institutions, cultures of respiratory secretions were conducted in the Bacteriological Laboratory of HUPE/UERJ, according to standardized protocols established for CF patients, and were performed at least on a 3- monthly basis throughout the study [5]. The clinical samples were plated onto Sheep blood agar, MacConkey agar, Mannitol salt agar (Difco Labs, Detroit, MI, USA) and Burkholderia cepacia medium supplemented (Oxoid, Basingstoke, England). The microorganisms were characterized at the genus and species level by routine conventional physiological methods [6]. In order to identify the distinct genomovars, a $1043 \mathrm{bp}$ PCR product corresponding to the recA gene was amplified by PCR. DNA sequence was performed in both directions with the PCR primers and the aid of two additional primers, BCR3 and $\mathrm{BCR}$, as previously described $[7,8]$.

Patients' inclusion criteria were: CF diagnosis according to Cystic Fibrosis Foundation consensus [9, 10]; regular clinical and laboratorial follow-up during the study period; chronic colonization with $P$. aeruginosa diagnosis (i.e., happened before the study period and was diagnosed when $P$. aeruginosa was isolated in more than $50 \%$ of cultures of sputum or throat swabs taken in the previous 12-month period) [11]. Subjects who presented no respiratory colonization or solely $S$. aureus colonization were excluded from the study, as well as those who were being submitted to any kind of P. aeruginosa eradication protocol.

These patients (all chronically colonized with P. aeruginosa) were divided into the following groups:

Group I - patients with intermittent colonization with BCC (1 or 2 isolates per year)

Group II - patients with chronic colonization with

$\mathrm{BCC}$ (3 or more isolates per year)

Group III - patients never colonized with BCC
For each patient, medical record data was evaluated, including gender, age, genotype and diagnostic criteria, state of pancreatic insufficiency (fecal fat or fecal elastase or need for exogenous replacement enzymes), CFrelated diabetes (CFRD) and liver disease. The clinical outcome of each patient was also evaluated considering the following parameters: spirometric parameters such as forced expiratory volume in $1 \mathrm{~s}\left(\mathrm{FEV}_{1}\right) \%$ predicted and forced vital capacity (FVC) \% predicted, and body mass index (BMI) percentile for patients 2-19 y/o. These data were recorded for all groups during three different times (Fig. 1): Time 1: when patient was diagnosed as having $P$. aeruginosa chronic colonization; Time 2: when group II was diagnosed as having chronic colonization with $\mathrm{BCC}$; since median time between the chronic colonization with $P$. aeruginosa and the chronic colonization with $\mathrm{BCC}$ was 3 years, this period of time was used to establish Time 2, for groups I and III; Time 3: all patients were also evaluated 5 years after the $P$. aeruginosa chronic colonization.

Descriptive statistical analyses were performed through construction of tables and charts. Non-parametric Mann-Whitney and Kruskal-Wallis tests were used to compare numerical and categorical variables with 2 or 3 categories respectively. The Wilcoxon test was used to analyze statistical significance of temporal variations within each group. The level of significance was set at probability (p) less than $5 \%(\mathrm{p}<0.05)$.

\section{Results}

From 2004 to 2013, 56 patients with chronic P. aeruginosa colonization were identified. Of these, 27 also had evidence of BCC colonization: 13 had intermittent colonization and 14 had chronic colonization. Clinical data is described in Table 1. Age of patients at the inclusion time ranged from 0 to 36 years old, most of them female $(n=38,67.9 \%)$; the majority were children or adolescents $(n=52 ; 92.9 \%)$. Diabetes mellitus (CFRD) and liver disease related to CF were uncommon (3.6 and $1.8 \%$, respectively), whereas pancreatic insufficiency was present

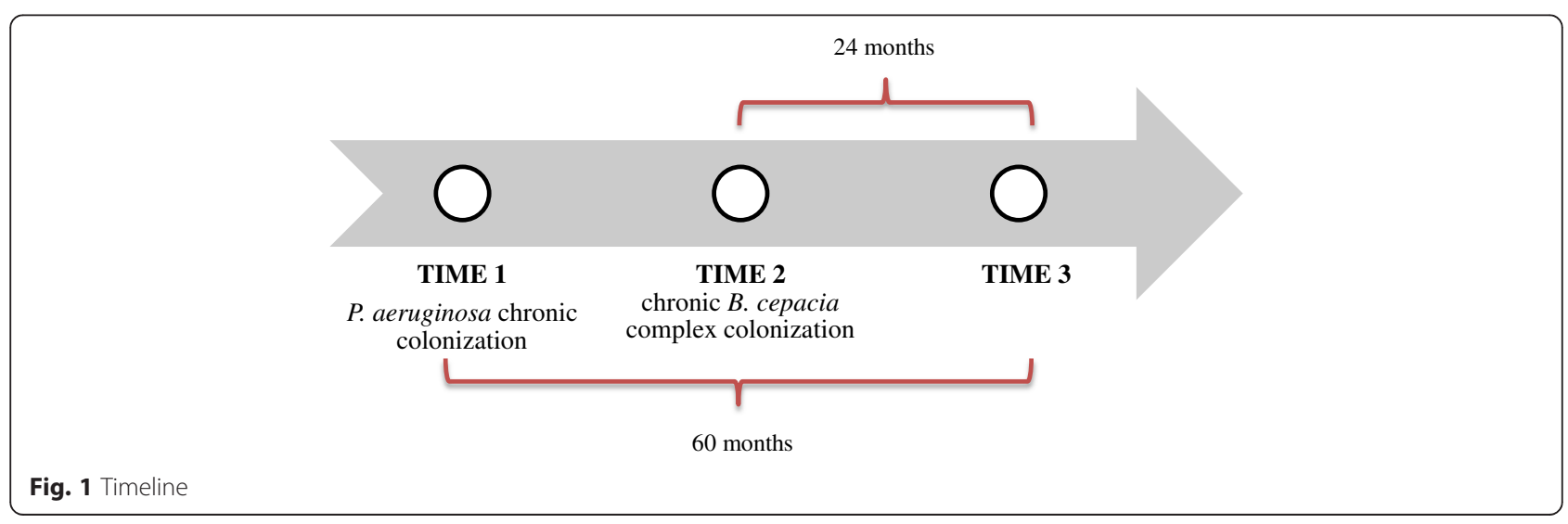


Table 1 Patient data

\begin{tabular}{lcccc}
\hline & Group I & Group II & Group III & $0.056^{*}$ \\
\hline Gender $(n)$ & & & 6 & \\
Male & 4 & 8 & 23 & 9.4 \\
$\quad$ Female & 9 & 6 & 11.1 & 0.5 \\
Age (mean age at time 1, in years) & 9.2 & 0.7 & $0.744^{* *}$ \\
Mean annual hospital admissions per year & 1.2 & $0.601^{* *}$ \\
\hline
\end{tabular}

in most of the population (94.6\%). Regarding chronic colonization, no patients were chronically colonized for $H$. Influenzae, Achromobacter spp and Stenotrophomonas spp. Chronic colonization with S. aureus was found in $84.6 \%$ in group I, $28.5 \%$ in group II and $92.6 \%$ in group III. Furthermore, chronic colonization with methicillin-resistant $S$. aureus was found in $7.7 \%$ in group I, $0 \%$ in group II and $7.4 \%$ in group III.

The average number of hospital admissions per year was 0.7 , with no statistical difference among the groups. At each hospital admission, patients received intravenous antibiotic treatment. All patients with new growths of $\mathrm{BCC}$ were treated with a regimen of 3 intravenous antibiotics (meropenem + ceftazidime + amykacin) for 2 weeks, followed by 3 consecutive months of nebulised tobramycin. If BCC is isolated after initial colonization, patients received another course of step I. For further CBC isolation, therapeutic management was discussed by the multidisciplinary team. Death occurred in 7 patients (2 in group I and 5 in group II). No patient died in group III during the 5 years of observation.

Spiromeric data $\left(\mathrm{FEV}_{1} \%\right.$ and FVC \% predicted) and BMI percentile were evaluated for all groups in the three different times previously described. Spirometric data were obtained from 49 of the 56 patients involved in the study: 10 of 13 patients in group I, 13 of the 14 patients in group II and 26 of the 29 patients in group III. The limiting factors for spirometry performance were: age less than six years old (6 patients), and neurological problems (1 patient).

There was no statistically significant difference between the groups for $\mathrm{FEV}_{1} \%$ predicted (p-value: 0.267) or FVC (p-value: 0.911 ) at the time of $P$. aeruginosa chronic infection. However, at this time, patients of group II (who would course with chronic colonization with BCC 3 years later) already presented BMI percentiles significantly lower (mean: 17.8) than the other groups (mean: 41.4 and 53.9), and p-value was 0.002 (Table 2).

Three years later, when patients from group II were diagnosed with chronic infection by $\mathrm{BCC}$, mean values of $\mathrm{FEV}_{1} \%$ predicted, $\mathrm{FVC} \%$ predicted and BMI percentile were lower in group II, without statistical significance $(p$-value $>0.05)$ (Table 2$)$.
Five years later, mean values of $\mathrm{FEV}_{1} \%$ predicted and FVC \% predicted were significantly lower in patients chronically colonized with BCC (52.3 \%; $67.8 \%)$ when compared with those with intermittent colonization by $\mathrm{BCC}$ and those never colonized with BCC ( $\mathrm{p}$-values 0.004 and 0.032 , respectively). Surprisingly, mean values of $\mathrm{FEV}_{1} \%$ predicted and $\mathrm{FVC} \%$ predicted for patients with intermittent $\mathrm{BCC}$ colonization were higher than those who were never colonized by BCC. At the end of the study (5 years after the $P$. aeruginosa chronic colonization), the mean value of the BMI percentile was significantly lower in patients with chronic BCC (21.1) than it was in groups I and III (45.4 and 45.6, respectively) with p-value 0.035 (Table 2).

Mean annual rates of decline for spirometric data $\left(\mathrm{FEV}_{1}\right.$ and $\mathrm{FVC} \%$ predicted) were statistically different between the groups. While group I (intermittent colonization with BCC) and III (never colonized with $\mathrm{BCC}$ ) showed mean $\mathrm{FEV}_{1} \%$ predicted annual rates of decline of $0 \pm 2.9 \%$ and $-2.6 \pm 2.9 \%$ respectively, patients chronically colonized with BCC presented with a mean FEV1 \% predicted annual rate of decline of $-6 \pm$ $6.0 \%$. When assessing FVC \% predicted, mean annual rates of decline in intermittent or never colonized patients with BCC were $0.6 \pm 2.5 \%$ and $-2.2 \pm 2.9 \%$, respectively, while patients chronically colonized with BCC presented with $-6 \pm 7.9 \%$ (Table 3).

In a subanalysis restricted to patients chronically colonized with $B$. cepacia complex bacteria, it was found that most of them had B. cenocepacia $(n=8)$ and B. vietnamiensis $(n=5)$. Analyzing spirometric data of $\mathrm{FEV}_{1}$ and FVC \% predicted, there were no statistical differences between species in this group of patients. However, we noted a greater number of deaths in $B$. cenocepacia chronically colonized patients.

\section{Discussion}

Previous studies have found that CF patients chronically colonized with $\mathrm{BCC}$ have a greater deterioration of lung function, require more frequent antibiotic therapy and also display increased mortality compared to patients colonized with $P$. aeruginosa $[12,13]$. 
Table 2 Espirometric and BMI percentile data

\begin{tabular}{|c|c|c|c|c|c|c|c|c|c|c|}
\hline \multirow[b]{2}{*}{ Parameters } & \multirow[b]{2}{*}{ Groups } & \multicolumn{3}{|l|}{ TIME 1} & \multicolumn{3}{|l|}{ TIME 2} & \multicolumn{3}{|l|}{ TIME 3} \\
\hline & & $\begin{array}{l}\text { Mean } \\
\text { values }\end{array}$ & $\begin{array}{l}\text { Standard } \\
\text { deviation }\end{array}$ & $P$-value & $\begin{array}{l}\text { Mean } \\
\text { values }\end{array}$ & $\begin{array}{l}\text { Standard } \\
\text { deviation }\end{array}$ & $P$-value & $\begin{array}{l}\text { Mean } \\
\text { values }\end{array}$ & $\begin{array}{l}\text { Standard } \\
\text { deviation }\end{array}$ & $P$-value \\
\hline \multirow[t]{4}{*}{$\mathrm{FEV}_{1} \%$} & 1 & 78.9 & 27.0 & 0.267 & 82.9 & 27.9 & 0.176 & 86.6 & 22.3 & 0.004 \\
\hline & $\|$ & 70.6 & 17.2 & & 66.4 & 22.4 & & 52.3 & 20.1 & \\
\hline & III & 81.5 & 22.2 & & 72.6 & 22.3 & & 67.0 & 18.8 & \\
\hline & Total & 78.2 & 21.8 & & 73.1 & 23.7 & & 66.7 & 22.5 & \\
\hline \multirow[t]{4}{*}{ FVC \% } & 1 & 85.5 & 24.2 & & 88.9 & 23.4 & & 93.6 & 18.7 & 0.032 \\
\hline & $\|$ & 86.5 & 18.3 & 0.911 & 80.8 & 18.7 & 0.426 & 67.8 & 21.2 & \\
\hline & III & 89.3 & 19.2 & & 82.0 & 19.4 & & 78.0 & 16.7 & \\
\hline & Total & 87.9 & 19.4 & & 83.1 & 19.9 & & 78.1 & 19.9 & \\
\hline \multirow[t]{4}{*}{ BMI percentile } & । & 41.4 & 25.4 & & 43.5 & 26.9 & & 45.4 & 20.8 & 0.035 \\
\hline & $\|$ & 17.8 & 19.5 & 0.002 & 22.3 & 20.5 & 0.082 & 21.1 & 15.0 & \\
\hline & III & 53.9 & 30.3 & & 45.7 & 29.2 & & 45.6 & 28.4 & \\
\hline & Total & 42.2 & 30.6 & & 39.8 & 28.1 & & 39.8 & 26.1 & \\
\hline
\end{tabular}

Group I: patients with intemittent colonization with $B$. cepacia complex bacteria ( 1 or 2 isolates per year)

Group II: patients with chronic colonization with $B$. cepacia complex bacteria ( $\geq 3$ isolates per year)

Group III: patients never colonized with B. cepacia complex bacteria

$\mathrm{FEV}_{1} \%$ : forced expiratory volume in $1 \mathrm{~s} \%$ predicted

FVC \%: forced vital capacity \% predicted

BMI percentile: body mass index percentile

$p$-value obtained by Wilcoxon test (level of significance: $p$-value $<0.05$ )

Although the clinical outcome after chronic $P$. aeruginosa colonization has been extensively analyzed and associated with deterioration of lung function, few studies have been done with chronic BCC colonization. McCloskey et al [14] assessed the impact of BCC infection in adult $\mathrm{CF}$ patients by measuring changes in pulmonary function and BMI in patients previously infected or never infected with $P$. aeruginosa. They concluded that infection with BCC results in a more rapid but variable lung function decline, which may be related to the strain involved. However, in all groups involved, there was no mention about chronicity of infection.
Correia et al [2] carried out a retrospective study of 31 patients with $\mathrm{BCC}$ infection who were categorized into two groups (I: intermittent isolations and II: chronic isolations). As expected, in the chronic isolation group, patients had higher mortality and number of hospitalizations and lower $\mathrm{FEV}_{1}$ values, in line with patients' major deterioration. Some patients from the chronic isolation group had already exhibited deteriorated lung function before becoming infected with $\mathrm{BCC}$, as a result of colonization with other pathogenic agents and disease progression. There was no comparative data between both groups regarding co-infection, lung function or BMI.

Table 3 Spirometric data (Annual rate of decline: FEV $1 \%$ and FVC \% predicted)

\begin{tabular}{|c|c|c|c|c|c|}
\hline & Group & Number & Mean & Standard deviation & $P$-value Kruskall-Wallis \\
\hline \multirow[t]{4}{*}{$\mathrm{FEV}_{1} \%$} & I & 10 & 0.0 & 2.9 & 0.002 \\
\hline & $\|$ & 13 & -6.0 & 6.6 & \\
\hline & III & 26 & -2.6 & 2.9 & \\
\hline & Total & 49 & -3.0 & 4.6 & \\
\hline \multirow[t]{4}{*}{ FVC \% } & I & 10 & 0.6 & 2.5 & 0.010 \\
\hline & $\|$ & 13 & -6.0 & 79 & \\
\hline & III & 26 & -2.2 & 2.9 & \\
\hline & Total & 49 & -2.6 & 5.2 & \\
\hline
\end{tabular}

Number: number of patients who performed spirometry

Group I: patients with intermittent colonization with $B$. cepacia complex bacteria ( 1 or 2 isolates per year)

Group II: patients with chronic colonization with $B$. cepacia complex bacteria ( $\geq 3$ isolates per year)

Group III: patients never colonized with $B$. cepacia complex bacteria

$\mathrm{FEV}_{1} \%$ : forced expiratory volume in $1 \mathrm{~s}$

FVC \%: forced vital capacity

Level of significance $p$-value $<0.05$ 
In our study, a higher number of deaths occurred in the BCC chronically colonized group. All patients in our study were previously diagnosed as having $P$. aeruginosa chronic infection. This aspect is relevant because the deterioration of any criteria in all groups wouldn't be associated with Pseudomonas aeruginosa, a bacteria currently known to have impact on CF lung disease, and, therefore, eliminating this possible bias [4].

Patients who developed chronic colonization with BCC demonstrated significant lower $\mathrm{FEV}_{1}$ and FVC at this time, showing that $B$. cepacia complex chronic colonization might be a risk factor for lung volume decline. Higher mean values of $\mathrm{FEV}_{1}$ and FVC were found for patients with intermittent $B$. cepacia complex colonization. This might be related to a better patient and family adherence to treatment since first isolation of B. cepacia complex. The knowledge of the decrease in long-term survival and fear of progressive invasive bacteremic disease associated with BCC colonization might be responsible for this change in attitude regarding CF treatment.

The rate of decline in $\mathrm{FEV}_{1} \%$ predicted has been studied in CF patients to better understand the progression of lung disease, in order to identify high-risk groups in whom aggressive therapy might be indicated and to assess therapeutic interventions. Risk factors associated with $\mathrm{FEV}_{1}$ decline include but are not limited to young age, high lung function, female gender, modifier genes, pancreatic insufficiency, poor nutritional status, viral respiratory infections, colonization with $P$. aeruginosa and BCC, and diabetes mellitus. The Epidemiologic Study of Cystic Fibrosis found that overall rates of $\mathrm{FEV}_{1} \%$ predicted decline were $-1.12,-2.39$ and $-2.34 \%$ per year in 6-8-year-olds, 9-12-year-olds and 13-17-year-olds, respectively [15].

Frangolias et al [16], comparing two groups of adult CF patients (infected and not infected with BCC), found no significant differences in rates of $\mathrm{FEV}_{1}$ and $\mathrm{FVC} \%$ predicted decline between cases and controls. In our study, mean rates of $\mathrm{FEV}_{1} \%$ predicted decline were statistically different between the groups, and the group chronically colonized with BCC presented with a mean $\mathrm{FEV}_{1} \%$ predicted decline of $-6 \%$ per year, which was much higher than expected in all ages. This shows the negative impact of chronic $B C C$ infection in $C F$ lung disease.

The association of better nutritional status with improvement of lung function is well documented, and poor nutrition is a risk factor for accelerated decline in lung function. However, it is not known whether BMI decline predates $\mathrm{FEV}_{1}$ decline. A retrospective study by Mc Phail et al [17] compared lung function and nutritional outcome in two CF birth cohorts. They found improvements in lung function and nutritional status in patients from ages
6-12, and a decreased rate of lung function decline associated with a higher baseline BMI (\% predicted) and a slower rate of BMI decline. In our study, the BCC chronically colonized group had a lower baseline BMI, which might be a risk factor for chronic $\mathrm{BCC}$ colonization and disease progression.

Many studies have shown that in pulmonary colonization with $B$. cepacia complex, the outcome varies considerably, from a rapid fatal decline in lung function and bacteremia to an acceleration of pulmonary function decline or to chronic asymptomatic infection, suggesting that pathogenicity within $B$. cepacia complex varies [12]. In our study, $B$. cenocepacia was more frequent in the chronically colonized group (8/14). In this group, the number of deaths was higher and associated with $B$. cenocepacia colonization in $80 \%$ of cases $(4 / 5)$. B. vietnamiensis was isolated in one patient of group II who died (1/5). Mean time of death after chronic colonization with BCC was 5.2 years. Considering only the four patients with $B$. cenocepacia colonization, this time was reduced to 4.7 years.

Understanding functional consequences of CFTR mutations is important not only for population screening but also CF for management and treatment. McManus et al [18] performed genotype analysis on 59 adult CF patients and evaluated its correlation to $P$. aeruginosa and BCC chronic infection. They concluded that patients homozygous or heterozygous for the deltaF508 deletion are more likely to suffer airway colonization with BCC or P. aeruginosa. In our study, CF genotype was not available for all patients. Further evaluation of CF genotype will be useful to understand correlation of CF genotype and BCC colonization.

The retrospective nature of the study and the strict inclusion criteria limited the sample size. However, there are few studies contemplating BCC infection involving children and adults with CF.

\section{Conclusion}

In conclusion, this study suggests that in patients previously identified as chronically colonized with $P$. aeruginosa, chronic BCC colonization is associated with lower spirometric data. However, lower BMI might preceed spirometric effects of $\mathrm{BCC}$, possibly being a risk factor for chronic colonization.

\section{Abbreviations}

BCC: Burkholderia cepacia complex; BMI: Body mass index; CF: cystic fibrosis; CFRD: CF-related diabetes; FEV : forced expiratory volume in $1 \mathrm{~s}$; FVC: forced vital capacity; HUPE: Hospital Universitário Pedro Ernesto; UERJ: Universidade do Estado do Rio de Janeiro.

\section{Competing interests}

The authors declare that they have no competing interests.

\section{Authors' contributions}

TWF, CHC and EAM conceived the study, its design and coordination. TWF and RWFC collected and analyzed data. OCCN and RMA carried out the 
microbiology analysis of respiratory secretions. TWF, CHC, EAM, RWFC, OCCN and RMA participated in the draft of the manuscript. All authors read and approved the final manuscript.

\section{Acknowledgements}

We would like to thank Ronir Raggio, PhD, who helped with statistical analysis.

\section{Author details}

'Department of Pediatric Pulmonology, Instituto Fernandes Figueira (Fundação Oswaldo Cruz, Ministério da Saúde), Av. Rui Barbosa, 716, 2nd floor, Flamengo, Zip Code: 22250-020 Rio de Janeiro, RJ, Brazil. ${ }^{2}$ Department of Pulmonology, Universidade do Estado do Rio de Janeiro/UERJ, Rio de Janeiro, RJ, Brazil. ${ }^{3}$ Department of Microbiology, Hospital Central da Aeronáutica, Rio de Janeiro, RJ, Brazil. ${ }^{4}$ Department of Biochemistry, Universidade do Estado do Rio de Janeiro/UERJ, Rio de Janeiro, RJ, Brazil. ${ }^{5}$ Department of Microbiology, Universidade do Estado do Rio de Janeiro/ UERJ, Rio de Janeiro, RJ, Brazil.

Received: 16 July 2015 Accepted: 20 November 2015

\section{Published online: 08 December 2015}

\section{References}

1. Gibson RL, Burns JL, Ramsey BW. Pathophysiology and management of pulmonary infections in cystic fibrosis. Am J Resp Crit Care Med. 2003; 168(8):918-51.

2. Correia S, Nascimento C, Pereira L, Cunha MV, Sá-Correia I, Barreto C. The clinical course of Burkholderia cepacia complex bacteria respiratory infection in cystic fibrosis patients. Rev Port Pneumol. 2008;14(1):5-26.

3. Eberl L, Tummler B. Pseudomonas aeruginosa and Burkholderia cepacia in cystic fibrosis: genome evolution, interactions and adaptation. Int J Microbiol. 2004;294:123-31.

4. Zemanick ET, Harris JK, Conway S, Konstan MW, Marshall B, Quittner AL, et al. Measuring and improving respiratory outcomes in cystic fibrosis lung disease: opportunities and challenges to therapy. J Cyst Fibros. 2010;9(1):1-16

5. Gilligan PH, Kiska DL, Appleman MD. Cumitech 43, cystic fibrosis microbiology. Washington, DC: ASM Press; 2006.

6. Gilligan PH. Infections in patients with cystic fibrosis: diagnostic microbiology update. Clin Lab Med. 2014;34(2):197-217.

7. Mahenthiralingam E, Bischof J, Byrne SK, Radomski C, Davies JE, Av-Gay Y, et al. DNA-based diagnostic approaches for identification of Burkholderia cepacia complex, Burkholderia vietnamiensis, Burkholderia multivorans, Burkholderia stabilis, and Burkholderia cepacia genomovars I and III. J Clin Microbiol. 2000;38:3165-73.

8. Carvalho GM, Carvalho AP, Folescu TW, Higa L, Teixeira LM, Plotkowski MC, et al. Transient isolation of Burkholderia multivorans and Burkholderia cenocepacia from a Brazilian cystic fibrosis patient chronically colonized with Burkholderia vietnamiensis. J Cyst Fibros. 2005;4(4):267-70.

9. Rosenstein B, Cutting G. The diagnosis of cystic fibrosis: a consensus statement. Cystic Fibrosis Foundation Consensus Panel. J Pediatr. 1998;132: 589-95.

10. Farrell PM, Rosenstein BJ, White TB, Accurso FJ, Castellani C, Cutting GR, et al. Guidelines for diagnosis of cystic fibrosis in newborns through older adults: Cystic Fibrosis Foundation consensus report. J Pediatr. 2008;153:S4-14.

11. Lee TWR, Brownlee KG, Convay SP, Denton M, Littlewood JM. Evaluation of a new definition of chronic $P$. aeruginosa infection in cystic fibrosis. J Cyst Fibros. 2003;2:29-34.

12. Courtney JM, Dunbar KEA, Mc Dowel A, Moore JE, Warke TJ, Stevenson M, et al. Clinical outcome of Burkholderia cepacia complex in cystic fibrosis adults. J Cyst Fibros. 2004:3:93-8.

13. Correa-Ruiz A, Girón R, Buendía B, Medina-Pascual MJ, Valenzuela C, López-Brea M, et al. Burkholderia cepacia complex infection in an adult cystic fibrosis unit in Madrid. Enferm Infecc Microbiol Clin. 2013;31(10):649-54.

14. McCloskey M, McCaughan J, Redmond AO, Elborn JS. Clinical outcome after acquisition of Burkholderia cepacia in patients with cystic fibrosis. Ir J Med Sci. 2001:170(1):28-31.

15. Konstan MW, Morgan WJ, Butler SM, Pasta DJ, Craib ML, Silva SJ, et al. Risk factors for rate of decline in forced expiratory volume in one second in children and adolescents with cystic fibrosis. J Pediatr. 2007;151(2):134-9.
16. Frangolias DD, Mahenthiralingham E, Rae S, Raboud JM, Davidson AGF, Wittman R, et al. Burkholderia cepacia in cystic fibrosis: variable disease course. Am J Respir Crit Care Med. 1999;160:1972-7.

17. McPhail GL, Acton JD, Fenchel MC, Amin RS, Seid M. Improvements in lung function outcomes in children with cystic fibrosis are associated with better nutrition, fewer chronic pseudomonas aeruginosa infections, and dornase alfa use. J Pediatr. 2008;153(6):752-7.

18. McManus TE, Beattie D, Graham C, Moore JE, Elborn JS. Cystic fibrosis genotype and bacterial infection: a possible connection. Br J Biomed Sci. 2005;62(2):85-8

\section{Submit your next manuscript to BioMed Central and we will help you at every step:}

- We accept pre-submission inquiries

- Our selector tool helps you to find the most relevant journal

- We provide round the clock customer support

- Convenient online submission

- Thorough peer review

- Inclusion in PubMed and all major indexing services

- Maximum visibility for your research 